2016-06

\title{
Long-term modifications of coastal defences enhance marine biodiversity
}

\author{
Martins, GM
}

http://hdl.handle.net/10026.1/8165

10.1017/S0376892915000284

ENVIRONMENTAL CONSERVATION

Cambridge University Press (CUP)

All content in PEARL is protected by copyright law. Author manuscripts are made available in accordance with publisher policies. Please cite only the published version using the details provided on the item record or document. In the absence of an open licence (e.g. Creative Commons), permissions for further reuse of content should be sought from the publisher or author. 
2 This is a copy of the accepted paper as submitted for final publication. The final published version can be found at:

4 http://onlinelibrary.wiley.com/wol1/doi/10.1111/maec.12354/full

6

LONG-TERM MODIFICATIONS OF COASTAL DEFENCES ENHANCE MARINE BIODIVERSITY

10

12

GUSTAVO M. MARTINS ${ }^{1,2^{*}}$, STUART R. JENKINS ${ }^{3}$, ANA I. NETO $^{1,2}$, STEPHEN J. HAWKINS ${ }^{4,5}$, RICHARD C. THOMPSON 6

141 CIIMAR/CIMAR - Interdisciplinary Centre of Marine and Environmental Research, University of Porto, Rua dos Bragas 289, 4050-123 Porto, Portugal

162 CIRN \& Grupo de Biologia Marinha, Departamento de Biologia, Universidade dos Açores, 9501-801 Ponta Delgada, Azores, Portugal

183 School of Ocean Sciences, Bangor University, Menai Bridge, Anglesey LL59 5AB, UK

204 Marine Biological Association of the United Kingdom, Citadel Hill, Plymouth PL1 2PB, UK

225 Ocean and Earth Science, National Oceanography Centre Southampton, University of Southampton, Waterfront Campus, Southampton SO14 3ZH, UK

246 Marine Biology and Ecology Research Centre, Marine Institute, Plymouth University, Plymouth PL4 8AA, UK

26

*EMAIL: gmartins@uac.pt 
Wordcount: 5817

\section{SUMMARY}

34 Realisation that hard coastal infrastructures support lower biodiversity than natural habitats has prompted a wealth of research seeking to identify design enhancements offering ecological benefits. Some studies showed that artificial structures could be modified to increase levels of diversity. Most studies, however, only considered the short-term ecological effects of such modifications even though reliance on results from short-term studies may lead to serious misjudgements in conservation. In this study, we conducted a 7-year experiment to examine how the addition of small pits to otherwise

42 featureless seawalls could enhance the stocks of a highly exploited limpet. Modified areas of the seawall supported enhanced stocks of limpets 7 years

44 after the addition of pits. Modified areas of the seawall also supported a community that differed in the abundance of littorinids, barnacles and macroalgae compared to the controls. Responses to different treatments (numbers and size of pits) were species-specific and while some species responded directly to differences among treatments, others might have responded indirectly via changes in the distribution of competing species. This type of habitat enhancement can have positive long-lasting effects on the ecology of urban seascapes. Understanding of species interactions could be

52 used to develop a rule-based approach to enhance biodiversity. 
54 Keywords: Azores, coastal urbanisation, community structure, conservation, habitat enhancement, long-term, Patella

\section{INTRODUCTION}

58 The replacement of natural shores by hard coastal defence structures (e.g. seawalls, breakwaters, revetments, groynes) is increasing as a response to

60 the growing need to defend the coast from sea level rise and stormier seas (e.g. Airoldi et al. 2005; Moschella et al. 2005; Chapman 2006). Realisation

62 that these structures generally support lower biodiversity than natural habitats (e.g. Chapman 2003; Chapman 2006; Chapman \& Bulleri 2003; Moschella et al. 2005; Vaselli, Bulleri \& Benedetti-Cecchi 2008; Firth et al. 2013a; Browne \& Chapman 2014) has focused attention on designing structures that help

66 facilitate specific ecological outcomes (Firth et al. 2014).

68 In cases where natural shores are completely replaced by artificial habitats there will be an obvious loss of habitat and the species therein. However, even when species colonise such artificial structures, they can hardly be considered as surrogates for the natural shores they replace (see review by

72 Chapman \& Underwood 2011). For instance, there is now documented evidence that on such hard coastal defence structures (e.g. seawalls) there

74 can be changes in the composition of species assemblages (Bulleri et al. 2005; Moschella et al. 2005), abundances (Chapman 2003), size-structure and reproductive output of populations (Moreira et al. 2006) and competitive interactions (Jackson et al. 2008; Iveša et al. 2010). Moreover, less obvious 
changes in community structure can also be found on natural shores surrounded (Goodsell et al. 2007) or in the vicinity (e.g. Martins et al. 2009) of such artificial habitats.

82 Lack of habitat heterogeneity has been put forward as the main cause of the lower level of biodiversity generally observed on sea defence structures

84 (Chapman \& Underwood 2011). There is now mounting evidence that experimentally increasing the complexity and heterogeneity of otherwise

86 topographically simple surfaces, for example by including water-retaining features, pits and crevices, can substantially increase the biodiversity of the 88 structure (Chapman \& Blockley 2009; Firth et al. 2013b; Browne \& Chapman 2014; Firth et al. 2014). Modifications can also be tailored to increase the

90 abundances of species of economic interest (Martins et al. 2010). These studies generally support the idea that hard coastal defence structures can be

92 modified to support an increasing level of diversity and thus contribute toward the conservation and management of urbanised coastlines whilst providing

94 effective protection from sea-level rise and stormier seas.

96 A common feature of these studies, however, is that their duration is typically < 1 year (e.g. Martins et al. 2010; Browne \& Chapman 2014) and little is 98 known about how modifications made to coastal defence structures continue to influence community structure in the longer term, yet results from short100 term experiments may not mirror those in the longer-term (e.g. O'Connor \& Crowe 2005) and this may influence feasible management actions (Callahan 102 1984; Magnuson 1990). 
104 Patella candei d'Orbigny is endemic to Macaronesia where it is extensively exploited for human consumption. In the Canary Islands, for instance, $P$.

106 candei is virtually extinct, presumably due to over-exploitation (Côrte-Real et al. 1996; Navarro et al. 2005). In the Azores, P. candei stocks collapsed in the 108 mid-1980s (Hawkins et al. 2000) and may constitute the largest anthropogenic impact on Azorean coastal ecosystems, being correlated with archipelago-

110 wide changes in the balance between consumers and producers (Martins et al. 2008). In 1993, legislation established fishing protected zones (where the

112 collection of limpets is fully prohibited), seasonal fishing closures and minimum catch sizes but these have proved largely unsuccessful due to lack

114 of enforcement and the limpets still show signs of over-exploitation (Martins et al. 2011).

In 2006, experimental habitat enhancements, consisting of the addition of pits

118 differing in size drilled into seawalls at different densities, showed that over the short-term (4 months) the abundance of limpets increased in enhanced

120 areas of the seawall (in comparison to unmanipulated controls) as a result of both animal immigration and new recruitment (Martins et al. 2010). Overall

122 effects of pit density and size varied with limpet size class, with the numbers of large limpets being limited by the availability of pits of the larger size,

124 whereas small limpets were limited by the density of pits of whatever size. Here we re-surveyed the experiment to evaluate effects of experimental

126 habitat enhancement on the abundances of the limpet $P$. candei after seven years. We also examined the wider community level impacts of changes in 
128 patellid limpet populations, because patellid limpets play a key community structuring role on European shores (e.g. Hawkins \& Hartnoll 1983; Jenkins et

130 al. 2005; Coleman et al. 2006), suggesting that variation in the distribution of limpets as a response to different habitat enhancements may have led to

132 community-wide effects. Moreover, different species of grazing gastropods have distinct influences on the community (e.g. Hawkins et al. 1989;

134 O’Connor \& Crowe 2005; Griffin et al. 2010).

\section{METHODS}

\section{Study sites and community}

138 The study area was São Roque (São Miguel Island, Azores), which has a gentle sloping basaltic rocky shore with many rock pools, that has been

140 largely replaced by the construction of a 4-5 km long seawall for shoreline protection . Our experimental habitat enhancement was applied to a seawall

142 made of $2 \mathrm{~m}$ wide natural basaltic blocks; these had smooth surfaces and lacked the micro-topographic rugosity characteristic of adjacent natural shores

144 (Martins et al. 2010). The experimental treatments were applied at mid-shore level just above the algal-dominated lower shore in areas where the barnacle

146 Chthamalus stellatus is the dominant space occupier and the limpet Patella candei reaches its largest abundance. Other patellid limpets ( $P$. aspera)

148 present on Azorean shores are not common at this tidal height. At this height, macroalgae are generally restricted to ephemeral species (e.g. Ulva spp.,

150 Chaetomorpha spp.) and a few perennial turf-forming algae (e.g.

Caulacanthus ustulatus). Other grazing gastropods, including the littorinids

152 Tectarius striatus and Melarhaphe neritoides, can also be locally abundant. 
154 At each of two sites $200 \mathrm{~m}$ apart, 25 areas of $25 \times 25 \mathrm{~cm}$ were marked and randomly assigned to 5 treatments. Five replicate areas were assigned to 156 unmanipulated controls. The remaining 20 areas were randomly assigned to a 2-way orthogonal design including the factors pit size (small and large) and pit

158 density (high and low) with five replicates per treatment. Small and large pits were 12 and $24 \mathrm{~mm}$ in diameter (both with a depth of $10 \mathrm{~mm}$ ). Lesser and 160 greater density treatments corresponded to 8 and 16 pits drilled within each area. Pits were drilled using an electrical power drill and were evenly spaced

162 within the experimental areas. The sizes and densities of pits used are within the range of sizes and densities of pits observed on natural shores (for further

164 details see Martins et al. 2010). The experimental habitat enhancement was established between November and December 2006.

\section{Sampling design}

168 Experimental areas were resurveyed in November 2013 (84 months after establishment) and March 2014 (87 months after establishment). During the

170 period of time between the start of the experiment and the initial sampling to determine short-term effects of habitat enhancements (see Martins et al.

172 2010) and the resurveys in 2013 and 2014, the experimental areas were left untouched and no sampling occurred. In November 2013, experimentally

174 enhanced plots were re-located and assessed to ensure that pits within experimental treatments were still evident and not masked by natural erosion.

176 At this time, the abundance of mobile gastropods (Patella candei, Tectarius striatus and Melarhaphe neritoides) within each area $(25 \times 25 \mathrm{~cm})$ was 
counted. Control areas were not evaluated and sampled at this time. In March 2014, we resurveyed the experiment and recounted all gastropods including

180 those in control areas. In addition, we estimated the percentage cover of sessile species (macroalgae and barnacles). For this purpose, we used a $25 \times$ $25 \mathrm{~cm}$ sampling quadrat divided in 25 sub-quadrats. Within each sub-quadrat, a score between 0 (absent) and 4 (full cover) was attributed to all species

184 present. Total percentage cover was obtained by summing the scores of the 25 subquadrats (see Dethier et al. 1993 for further details). Mobile animals

186 (limpets and littorinids) were counted as described above, and limpets were measured (shell maximum length) using a Vernier calliper. We were able to

188 find all areas except 3 control locations (marks were gone). We replaced these missing controls with 3 randomly selected areas scattered among

190 experimental areas. No attempt was made to sample communities surrounding the experimental areas $(25 \times 25 \mathrm{~cm})$ since the strongest

192 interacting species in this system, $P$. candei, exhibits a homing behaviour (Cacabelos unpublished data) and was thus unlikely to influence assemblage

194 structures a few centimetres away from the experimental areas.

\section{Data analysis}

A mixed model asymmetrical analysis of variance (ANOVA) was used to test

198 for differences in the abundance of taxa among experimental treatments using the factors 'site' (random) and 'among all' (fixed and orthogonal to site). The

200 latter was partitioned into 'control vs treatments', to compare the abundance of taxa in control areas to the average of the enhanced areas, and 'among 202 treatments'. In addition, the factor 'among treatments' was further 
decomposed and restructured to allow testing the effects of pit 'size' (fixed)

204 and 'density' (fixed and orthogonal to 'size'). These are effectively two separate analyses, which can subsequently be built together into a single ANOVA table. Residuals were also decomposed to match changes in the numbers of replicates for both analyses.

Prior to analysis, data were checked for heterogeneity of variances and

210 transformations were applied where necessary (Underwood 1997). StudentNewman-Keuls (SNK) tests were used a posteriori to examine for differences

212 within significant terms.

214 The variables analysed were the abundance of the gastropods (Patella candei, Tectarius striatus and Melarhaphe neritoides) and the percentage

216 cover of the barnacle Chthamalus stellatus and macroalgae. Prior to analysis, macroalgae were grouped into two morpho-functional groups (Steneck \&

218 Dethier 1994) uncorticated ephemeral algae including both filamentous (Chladophora spp.) and foliose (Ulva spp.) species (hereafter referred to as

220 ephemerals alone) and corticated perennial turfs such as Caulacanthus ustulatus (hereafter referred to as corticated turfs alone). Encrusting algae

222 were also present in some areas, but their overall abundance was very low (< $1 \%)$ and was not analysed. This analysis was applied to data sampled on

224 March 2014 as no controls were sampled during November 2013. A simple 3way ANOVA with 'site' 'pit density' and 'pit size' was used to analyse

226 November 2013. Results were similar between these two dates and we only 
present data from March 2014 for simplicity (analysis of November 2013 in Appendix S2).

230 The chi-squared test of independence (or association) was used to test the null hypothesis of no association between the frequency of the three species

232 of grazing gastropods and the experimental treatments. The mean number of each species in each of the four treatments was used as observed

234 frequencies, respectively.

236 We used Pearson's product-moment correlation to highlight potential relationships emerging from changes in the abundance of grazers as a 238 consequence of treatments on the abundance of sessile taxa.

\section{RESULTS}

\section{Enhanced vs control areas}

242 Analysis of the gastropod assemblages showed that all the three species (Patella candei, Tectarius striatus and Melarhaphe neritoides) were on

244 average, more abundant in enhanced areas of the seawall compared to unmanipulated controls (Fig. 1 A-C). This result was significant in the cases of 246 P. candei and T. striatus (Table S1 - Appendix S1), which were around 5 and 11 times more abundant in enhanced areas of the seawall, respectively.

248 Although the abundance of $M$. neritoides was over 2 times greater in enhanced areas of the seawall (Fig. 1C), no significant effect of seawall

250 modification was found (Table S1). The mean limpet biomass per plot (dry body weight estimated for each individual from an established length-mass 
252 relationship, see Martins et al., 2008) of $P$. candei was also approximately 5 times greater (mean limpet biomass in $\mathrm{mg} \pm \mathrm{SE}$, control: $38.2 \pm 17.2$,

254 enhanced areas: $182.9 \pm 30.4$ ) in enhanced areas of the seawall. When considering the entire grazing assemblage (all species together), there was on average a significantly greater number of grazers in enhanced areas of the seawall than in unmanipulated controls (Fig. 1D, Table S1).

Using SNK tests to examine for differences within the factor 'among all' (and not only the control to the average of enhanced areas) showed that, in comparison to controls, the numbers of limpets were effectively and

262 significantly greater in all of the enhanced treatments but one (small and low pit density)(Table S2 - Appendix S1). In the case of T. striatus, and despite

264 the significant effect detected between controls and the average of enhanced areas, SNK tests failed to find significant differences between control and all

266 the four enhanced treatments but one (small and low pit density)(Table S2).

268 Among the remainder of the assemblage, a significant difference was also found between controls and the average of enhanced areas in the abundance 270 of barnacles and corticated turfs (Table S1). These were nearly twice and 11 times more abundant in enhanced areas than in controls respectively (Fig.

$2722 \mathrm{~A}, \mathrm{~B})$. In contrast, the abundance of ephemerals was highly variable and did not respond consistently to treatments (Fig. 2C, Table S1)

Using SNK tests to examine for differences within the factor 'among all' (and not only the control to the average of enhanced areas) showed that, in 
comparison to controls, the abundance of barnacles was significantly greater in treatments with large pits, independently of their density (Table S2). For corticated turfs, results were spatially variable; at one site no difference was

280 found, whilst on the other site there were significant differences only between controls and areas with large and high density of pits (Table S2).

\section{Effects of pit size and density}

284 Species making up the gastropod assemblage had variable responses to the different treatments. The limpet $P$. candei responded positively to both the

286 density and size of pits (Fig. 1A), being significantly more abundant in enhanced areas with a higher density of pits and in areas with larger pits 288 (Table S1). In contrast, the littorinids $T$. striatus and $M$. neritoides did not respond to pit density, but were significantly more abundant in areas of the

290 seawall enhanced with small pits (Fig. 1B-C, Table S1). For M. neritoides this result was only detected at one of the sites examined.

Overall, the null hypothesis of no association between the gastropod

294 assemblage and the experimental treatments was rejected (Table 1). This result suggests that each enhancement treatment supports a structurally

296 divergent assemblage of grazers (Fig. 1D). This was especially evident in those treatments that differed the most (small pit size and low density vs large

298 pit size and high density) - as indicated by the relative chi-squared contribution of each treatment (Table 1). All the above patterns were also

300 present and similar 4 months earlier in November 2013 (Appendix S2) suggesting that this pattern was temporally consistent. 
When considering the remainder of the assemblage, the abundance of

304 barnacles was significantly greater in areas with large pits (Fig. 2A, Table S1). A significant interaction between site, pit density and pit size was detected in

306 the case of corticated turfs (Table S1). Inspection of Figure 2B suggests that these tended to increase in abundance with increasing pit area although

308 results were spatially variable (see SNK tests in Table S2).

The abundance of ephemerals also varied among enhancement treatments

310 (Fig. 2C). A significant interaction was found between site and pit density, and to lesser extent $(\alpha=0.10)$ between site and pit size (Table S1). SNK tests

312 showed that the abundance of ephemerals was greater in areas with lower pit density (Fig. 2C), although this was only significant at site 1 (Table S2).

Strong correlations were found between the abundance of barnacles, turfs

316 and ephemerals and P. candei (Table 2). The correlation was positive for barnacles and turfs, but negative between ephemerals and limpets. The

318 abundance of barnacles and ephemerals was also weakly positively correlated with $T$. striatus but there was a strong and negative correlation

320 between the later and the abundance of turfs (Table 2). All the sessile taxa (barnacles, turfs and ephemerals) showed a negative correlation with the 322 abundance of $M$. neritoides (Table 2).

\section{DISCUSSION}

\section{Long-term effects on the target species}


326 Our results suggest that those areas of the seawall that were experimentally modified to enhance the abundance of the highly exploited limpet Patella candei, have had a long-term impact. Although no sampling was done in between the two periods, our resurvey has shown that the short-term

330 enhancement of $P$. candei, observed by Martins et al (2010) has been maintained over a 7-year period. Thus the simple approach of drilling pits in

332 the rock is highly effective in promoting the abundance and biomass of this exploited species over many years; the abundance and biomass of $P$. candei

3347 years on was at least 5 times greater in enhanced compared to control areas of the seawall.

As with results from the short-term experiment (Martins et al. 2010), limpets responded differently to the different habitat enhancement treatments. Observations after 7 years indicate that limpet abundance as a whole (not

340 differentiating among different size classes; see Martins et al. 2010) was positively influenced by the abundance and size of pits, suggesting that particularly the availability of large pits is potentially a limiting factor. This information can thus be used when designing new infrastructure; in order to

344 enhance limpet stocks, emphasis should be placed on designing structures that offer a high density of pits of the larger size. It should be noted that the 346 larger individuals in this study were all able to fit within the larger pits. It is unclear what happens to animals larger than those that fit into pits. Such 348 larger animals may eventually seek other areas of the seawall as reliance on pits decreases with increasing animal size (Martins et al. 2010). Such larger 
350 individuals are, however, uncommon on Azorean shores due to overexploitation (Martins et al. 2008).

\section{Community-wide effects}

354 Even though the modifications made to the seawall were initially designed considering one specific species $(P$. candei), a longer-time perspective allows

356 examination of the influence on the structure of the entire assemblage, including littorinids, barnacles and macroalgae (see Fig. 2). When considering

358 littorinids, it is interesting to note that their response to the distinct treatments differed from that observed for limpets. While limpets appeared to be limited 360 by the availability of large pits, littorinids were more abundant in the smaller pits. Their abundance also did not appear to be limited by the density of pits in contrast to that found for limpets. This might reflect the gregarious nature of littorinids as several individuals of both $T$. striatus and $M$. neritoides were

364 often found sharing a single pit, as was also noted by Skov et al. (2011). This was uncommon among limpets that were generally found inhabiting pits

366 alone. This different behaviour between limpets and littornids likely reflects differences in the relative strength of intraspecific competition among these 368 gastropods (Underwood 1978).

370 Substantial variation in abundance of the other taxa (barnacles and macroalgae) was also observed among experimental treatments, especially in

372 relation to pit size. This suggests that the modifications made to the seawall may have also influenced species other than prosobranch gastropods. This is

374 not surprising as surface topography is known to affect the settlement by 
many organisms (e.g. Crisp 1955; Harlin \& Lindbergh 1977; Raimondi 1988). There is, however, an alternative explanation: that changes in the abundance of barnacles and macroalgae are an indirect effect of treatments through 378 changes in the structure of the grazer assemblage (e.g. Hartnoll \& Hawkins 1985; Lubchenco 1983; Farrell 1988; Johnson et al. 1998; Jenkins et al. 2005). For instance, the abundance of ephemeral algae, in contrast with that of limpets, tended to decrease with increasing pit area. Although in such areas there were also increased densities of littorinids, there was little difference in the community structure between these areas and the smooth

384 unmanipulated control areas of the seawall. This result suggests that littorinids have little influence on the overall structure of the community - as noted also by O'Connor \& Crowe (2005) and Griffin et al. (2010) - even though their abundance was enhanced by the addition of small pits. In contrast, areas of the seawall enhanced by the addition of large pits supported the most distinct community structure with a comparatively higher 390 abundance of limpets, corticated turfs and barnacles, and a lower abundance of ephemeral algae (Fig. 3). Unlike ephemeral algae, a positive correlation

392 was found between barnacles and corticated turfs and the abundance of limpets suggesting that the latter may facilitate their establishment. As is 394 widely known, intertidal limpets generally have a large negative effect on the abundance of ephemeral algae (Hawkins 1983; Van Tamelen 1987).

396 Ephemeral algae, in turn, can have an inhibitory effect of the establishment of perennial algae (e.g. Sousa 1979; Hawkins 1981; Viejo et al. 2008, Jenkins \& 398 Martins 2010). Selective removal of ephemerals by high density of limpets in areas of the seawall enhanced with large pits may have thus indirectly 
400 facilitated the establishment of barnacles and corticated perennial turfs (Hawkins \& Hartnoll 1983; Van Tamelen 1987; Benedetti-Cecchi 2000) (Fig.

402 4). Overall, these results appear to suggest that the changes seen in the community structure in areas of the seawall enhanced with the addition of

404 large pits may be a result of modifications to the network of interactions among intertidal species (as schematically represented in Figure 3).

\section{Conclusion}

408 The experimental modifications made to coastal engineering can have longlasting effects. This result is important from a conservation perspective and

410 reinforces the concept that simple modifications made to coastal defence structures, that are unlikely to affect structural integrity of the building blocks,

412 can be used as a lasting and effective tool for the conservation of species, provided that a solid understanding of the ecology of the focal species is

414 known. While the enhancement of unprotected coastal infrastructures may be pointless, many infrastructures actually have regulated access. In these

416 cases, coastal infrastructures may positively influence stocks of important species but also impact nearby areas via spill-over effects. Our results,

418 however, also suggest that the modifications to the seawalls can influence non-targeted species both directly, by affecting the spatial distribution of the 420 organisms, and indirectly, by affecting the spatial distribution of competitors and predators. Understanding the interactions between species can lead to a

422 rule-based approach to interventions to enhance biodiversity.

\section{Supplementary material}


For supplementary material accompanying this paper, visit

\section{ACKNOWLEDGMENTS}

The initial experiment was supported by Fundação para a Ciência e

430 Tecnologia (FCT) through a PhD grant awarded to GMM

(SFRH/BD/22009/2005). During this experiment, GMM was supported by a

432 post-doctoral grant awarded by FCT (SFRH/BDP/63040/2009). This research was partially supported by the European Regional Development Fund (ERDF)

434 through the COMPETE and Operational Competitiveness Programme and national funds through FCT, under the project "PEst-C/MAR/LA0015/2011".

436 The authors would like to thank Eva Cacabelos and João Faria for help during fieldwork.

\section{References}

440 Airoldi, L., Abbiati, M., Beck, M.W., Hawkins, S.J., Jonsson, P.R., Martin, D., Moschella, P.S., Sundelöf, A., Thompson, R.C. \& Åberg, P. (2005) An

442 ecological perspective on the deployment and design of low-crested and other hard coastal defence structures. Coastal Engineering 52: 1073-1087.

444 Benedetti-Cecchi, L. (2000) Predicting direct and indirect interactions during succession in a mid-littoral rocky shore assemblage. Ecological Monographs

446 70: $45-72$.

Browne, M.A. \& Chapman, M.G. (2014) Mitigating against the loss of species

448 by adding artificial intertidal pools to existing seawalls. Marine Ecology Progress Series 497: 119-129. 
450 Bulleri, F., Chapman, M.G. \& Underwood, A.J. (2005) Intertidal assemblages on seawalls and rocky shores in Sydney Harbour (Australia). Austral Ecology

$452 \quad 30: 655-667$.

Callahan, J.T. (1984) Long-term ecological research. BioScience 34: 363-367.

454 Chapman, M.G. (2003) Paucity of mobile species on constructed seawalls:

effects of urbanization on biodiversity. Marine Ecology Progress Series 264:

456 21-29.

Chapman, M.G. (2006) Intertidal seawalls as habitats for molluscs. Journal of

458 Molluscan Studies 72: 247-257.

Chapman, M.G. \& Blockley, D.J. (2009) Engineering novel habitats on urban

460 infrastructure to increase intertidal biodiversity. Oecologia 161: 625-635.

Chapman, M.G. \& Bulleri, F. (2003) Intertidal seawalls - new features of

462 landscape in intertidal environments. Landscape and Urban Planning 62: 159172.

464 Chapman, M.G. \& Underwood, A.J. (2011) Evaluation of ecological engineering of "armoured" shorelines to improve their value as habitat.

466 Journal of Experimental Marine Biology and Ecology 400: 302-313.

Clarke, K.R. \& Gorley, R.N. (2006) PRIMER v6. PRIMER-E, Plymouth.

468 Coleman, R.A., Underwood, A.J., Benedetti-Cecchi, L., Åberg, P., Arenas, F., Arrontes, J., Castro, J., Hartnoll, R.G., Jenkins, S.R., Paula, J., Della Santina,

470 P. \& Hawkins, S.J. (2006) A continental scale evaluation of the role of limpet grazing on rocky shores. Oecologia 147: 556-564.

472 Côrte-Real, H.B., Hawkins, S.J. \& Thorpe, J.P. (1996) Population differentiation and taxonomic status of the exploited limpet Patella candei in 
474 the Macaronesian Islands (Azores, Madeira, Canaries). Marine Biology 125: $141-152$.

476 Crisp, D.J. (1955) The behavior of barnacle cyprids in relation to water movement over a surface. Journal of Experimental Marine Biology and 478 Ecology 32: 569-590.

Dethier, M.N., Graham, E.S., Cohen, S. \& Tear, L.M. (1993) Visual versus 480 random-point percent cover estimations: "objective" is not always better. Marine Ecology Progress Series 96: 93-100.

482 Farrell, T.M. (1988) Community stability: Effects of limpet removal and reintroduction in a rocky intertidal community. Oecologia 75: 190-197.

484 Firth, L.B., Mieszkowska, N., Thompson, R.C. \& Hawkins, S.J. (2013a) Climate change and adaptational impacts in coastal systems: the case of sea 486 defences. Environmental Sciences: Processes and Impacts 15: 1665-1670. Firth, L.B., Thompson, R.C., Abbiati, M.A., Airoldi, L., Bouma, T.J., Bozzeda, 488 F., Ceccherelli, V.U., Colangelo, M.A., Evans, A., Ferrario, F., Hanley, M.E., Hinz, H., Hoggart, S.P.G., Jackson, J.E., Moore, P., Morgan, E.H., Perkil490 Finkel, S., Skov, M.W., Strain, E.M., van Belzen, J. \& Hawkins, S.J. (2014) Between a rock and a hard place: Environmental and engineering 492 considerations when designing coastal defence structures. Coastal Engineering 87: 122-135.

494 Firth, L.B., Thompson, R.C., White, F.J., Schofield, M., Skov, M.W., Hoggart, S.P.G., Jackson, J., Knights, A.M. \& Hawkins, S.J. (2013b) The importance of 496 water-retaining features for biodiversity on artificial intertidal coastal defence structures. Diversity and Distributions 19: 1275-1283. 
498 Goodsell, P.J., Chapman, M.G. \& Underwood, A.J. (2007) Differences between biota in anthropogenically fragmented habitats and in naturally

500 patchy habitats. Marine Ecology Progress Series 351: 15-23.

Griffin, J.N., Noel, L., Crowe, T., Burrows, M.T., Hawkins, S.J., Thompson,

502 R.C. \& Jenkins, S.R. (2010) Consumer effects on ecosystem functioning in rockpools: roles of species richness and composition. Marine Ecology

504 Progress Series 420: 45-56.

Harlin, M.M. \& Lindbergh, J.M. (1977) Selection of substrata by seaweeds:

506 optimal surface relief. Marine Biology 40: 33-40.

Hartnoll, R.G. \& Hawkins, S.J. (1985) Patchiness and fluctuations on

508 moderately exposed rocky shores Ophelia 24: 53-63.

Hawkins, S.J. (1981) The influence of season and barnacles on the algal

510 colonization of Patella vulgata exclusion areas. Journal of the Marine Biological Association of the UK 61: 1-15.

512 Hawkins, S.J. (1983) Interactions of Patella and macroalgae with settling Semibalanus balanoides (L.). Journal of Experimental Marine Biology and

514 Ecology 71: 55-72.

Hawkins, S.J., Côrte-Real, H.B.S.M., Pannacciulli, F.G., Weber, L.C. \&

516 Bishop, J.D.D. (2000) Thoughts on the ecology and evolution of the intertidal biota of the Azores and other Atlantic Islands. Hydrobiologia 440: 3-17.

518 Hawkins, S.J. \& Hartnoll, R.G. (1983) Grazing of intertidal algae by marine invertebrates. Oceanography and Marine Biology: An Annual Review 21: 195520282.

Hawkins, S.J., Watson, D.C., Hill, A.S., Harding, S.P., Kyriakides, M.A., 522 Hutchinson, S. \& Norton, T.A. (1989) A comparison of feeding mechanisms in 
microphagous, herbivorous, intertidal, prosobranchs in relation to resource partitioning. Journal of Molluscan Studies 55: 151-165.

Iveša, L., Chapman, M.G., Underwood, A.J. \& Murphy, R.J. (2010) Differential

526 patterns of distribution of limpets on intertidal seawalls: experimental investigation of the roles of recruitment, survival and competition. Marine

528 Ecology Progress Series 407: 55-69.

Jackson, A.C., Chapman, M.G. \& Underwood, A.J. (2008) Ecological

530 interactions in the provision of habitat by urban development: whelks and engineering by oysters on artificial seawalls. Austral Ecology 33: 307-316.

532 Jenkins, S.R., Coleman, R.A., Della Santina, P., Hawkins, S.J., Burrows, M.T. \& Hartnoll, R.G. (2005) Regional scale differences in the determinism of 534 grazing effects in the rocky intertidal. Marine Ecology Progress Series 287: 77-86.

536 Jenkins, S.R. \& Martins, G.M. (2010) Succession on hard substrata. In: Biofouling, eds S. Dürr S. \& J.C. Thomason, pp. 60-72. West-Sussex, UK:

538 Wiley-Blackwell. Johnson, M.P., Hughes, R.N., Burrows, M.T. \& Hawkins, S.J. (1998) Beyond

540 the predation halo: small scale gradients in barnacle populations affect the relative value of crevices. Journal of Experimental Marine Biology and

542 Ecology 231: 163-170.

Lubchenco, J. (1983) Littorina and Fucus: Effects of herbivores, substratum

544 heterogeneity, and plant escapes during succession. Ecology 64: 1116-1123. Magnuson, J.J. (1990) Long-term ecological research and the invisible 546 present. BioSciece 40: 495-501. 
Martins, G.M., Amaral, A.F., Wallenstein, F.M. \& Neto, A.I. (2009) Influence of

Environmental Research 67: 237-245.

550 Martins, G.M., Jenkins, S.R., Hawkins, S.J., Neto, I.A. \& Thompson, R.C. (2008) Exploitation of rocky intertidal grazers: population status and potential

552 impacts on community structure and functioning. Aquatic Biology 3: 1-10. Martins, G.M., Jenkins, S.R., Hawkins, S.J., Neto, A.I., Medeiros, A.R. \&

554 Thompson, R.C. (2011) Illegal harvesting affects the success of fishing closure areas. Journal of the Marine Biological Association of the United

$556 \quad$ Kingdom 91: 929-937.

Martins, G.M., Thompson, R.C., Neto, A.I., Hawkins, S.J. \& Jenkins, S.R.

558 (2010) Enhancing stocks of the exploited limpet Patella candei d'Orbigny via modifications in coastal engineering. Biological Conservation 143: 203-211.

560 Moreira, J., Chapman, M.G. \& Underwood, A.J. (2006) Seawalls do not sustain viable populations of limpets. Marine Ecology Progress Series 322:

$562 \quad 179-188$.

Moschella, P.S., Abbiati, M., Åberg, P., Airoldi, L., Anderson, J.M.,

564 Bacchiocchi, F., Bulleri, F., Dinesen, G.E., Frost, M., Gacia, E., Granhag, L., Jonsson, P.R., Satta, M.P., Sundelöf, A., Thompson, R.C. \& Hawkins, S.J.

566 (2005) Low-crested coastal defence structures as artificial habitats for marine life: using ecological criteria in design. Coastal Engineering 52: 1053-1071.

568 Navarro, P.G., Ramírez, R., Tuya, F., Fernandez-Gil, C., Sanchez-Jerez, P. \& Haroun, R.J. (2005) Hierarchical analysis of spatial distribution patterns of 570 patellid limpets in the Canary Islands. Journal of Molluscan Studies 71: 67-73. 
O'Connor, N.E. \& Crowe, T.P. (2005) Biodiversity and ecosystem functioning: distinguishing between effects of the number of species and their identities. Ecology 86: 1783-1796.

574 Raimondi, P.T. (1988) Rock type affects settlement, recruitment, and zonation of the barnacle Chthamalus anisopoma (Pilsbury). Journal of Experimental 576 Marine Biology and Ecology 123: 253-267.

Skov, M.W., Hawkins, S.J., Volkelt-Igoe, M., Pike, J., Thompson, R.C. \&

578 Doncaster, C.P. (2011) Patchiness in resource distribution mitigates habitat loss: insights from high-shore grazers. Ecosphere 2: 1-17.

580 Sousa, W.P. (1979) Experimental investigations of disturbance and ecological succession in a rocky intertidal algal community. Ecological Monographs 49:

$582 \quad 227-254$.

Steneck, R.S., Dethier, M.N. (1994) A functional group approach to the

584 structure of algal-dominated communities. Oikos 69: 476-498.

Underwood, A.J. (1978) An experimental evaluation of competition between

586 three species of intertidal prosobranch gastropods. Oecologia 33: 185-202. Underwood, A.J. (1997) Experiments in ecology: their logical design and

588 interpretation using analysis of variance. Cambridge University Press, Cambridge.

590 Van Tamelen, P.G. (1987) Early successional mechanisms in the rocky intertidal: the role of direct and indirect interactions. Journal of Experimental

592 Marine Biology and Ecology 112: 39-48.

Vaselli, S., Bulleri, F. \& Benedetti-Cecchi, L. (2008) Hard coastal-defence

594 structures as habitats for native and exotic rocky-bottom species. Marine Environmental Research 66: 395-403. 
596 Viejo, R.M., Arenas, F., Fernández, C. \& Gómez, M. (2008) Mechanisms of succession along the emersion gradient in intertidal rocky shore

598 assemblages. Oikos 117: 376-389.

Table 1. Results of $\chi^{2}$ tests of independence comparing the mean abundance 600 of grazers among treatments $\left(\chi^{2}\right.$ global $=30.26$, d.f. $\left.=4, P<0.001\right)$

\section{Species of grazers}

602

P. candei T. striatus

M. neritoides

Large, High

604 Observed

19.6

2.3

6.0

Expected

10.07

5.89

11.94

$606 \chi^{2}$ contribution

9.03

2.19

2.96

Large, Low

608 Observed

8.3

1.9

8.5

Expected

6.74

3.95

8.00

$610 \quad \chi^{2}$ contribution

0.36

1.06

0.03

Small, High

612 Observed

8.5

6.9

16.7

Expected

11.58

6.78

13.74

$614 \chi^{2}$ contribution

0.82

$<0.01$

0.64

Small, Low

616
Observed

1.2

10.9

13.4

Expected

9.20

5.38

10.91

$618 \chi^{2}$ contribution

6.96

5.65

0.57 
Table 2. Pearson's product-moment correlation coefficients between the

624 abundance of grazers and the sessile taxa in experimental enhanced areas of the seawall.

626

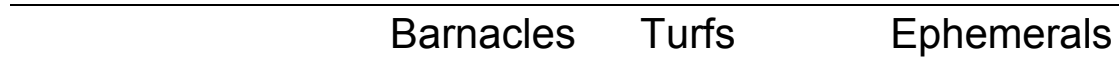

\begin{tabular}{llll}
\hline . candei $\quad+0.36$ & +0.36 & -0.31
\end{tabular}

628

$\begin{array}{llll}T . \text { striatus } & -0.03 & -0.27 & +0.08 \\ M . \text { neritodes } & -0.16 & -0.32 & -0.20\end{array}$

630

632

634

636

638

640

642

644 
648 Figure caption

Fig. 1. Mean (+SE) abundance each of the prosobranch gastropod species (a)
P. candei,
(b) T. striatus, (c)
(c) M. neritoides and
(d) their combined abundance, in unmanipulated controls and habitat-enhanced areas of the seawall in

652 November 2014. C - control, SL - small and low pit density, LL - large and low pit density, $\mathrm{SH}$ - small and high pit density, $\mathrm{LH}$ - large and high pit

654 density. In (d) bar length corresponds to the mean abundance of Patella candei (black), Tectarius striatus (grey) and Melarhaphe neritoides (white).

656 Data from the two sites was pooled together for clarity as there was no significant variation between sites (Table S1).

658

Fig. 2. Mean (+SE) percentage cover of (a) barnacles, (b) corticated turfs and 660 (c) ephemerals in November 2014. See legend on Figure 1.

662 Fig. 3. Conceptual representation of the possible network of interactions as result of habitat enhancement treatments. Continuous arrow - direct effect, 664 dashed arrow - indirect effect. Arrow thickness indicates the relative strength of effect; \pm indicates whether effects are negative or positive.

666 

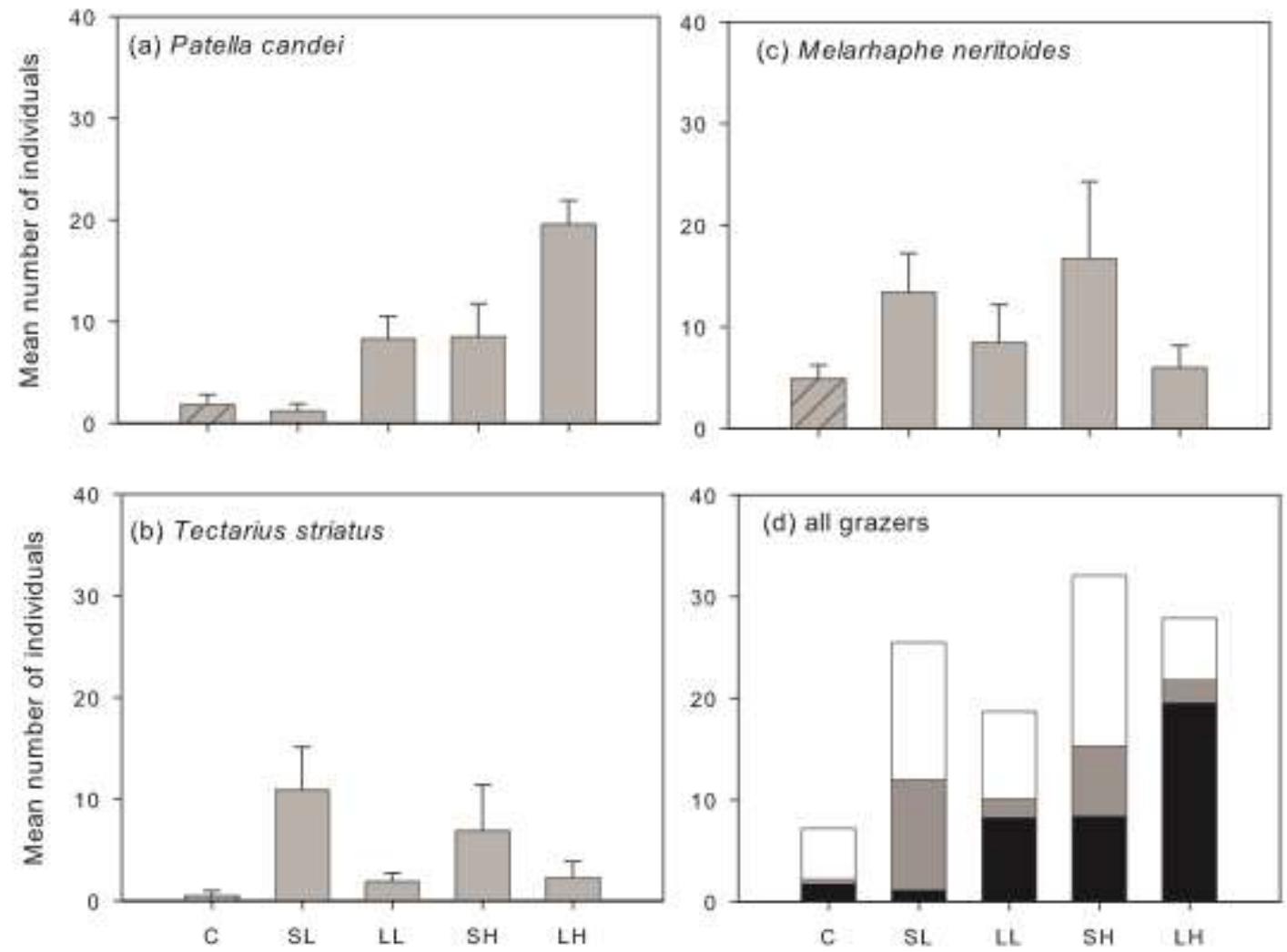

$674 \quad$ Fig. 1

676

678

680

682 

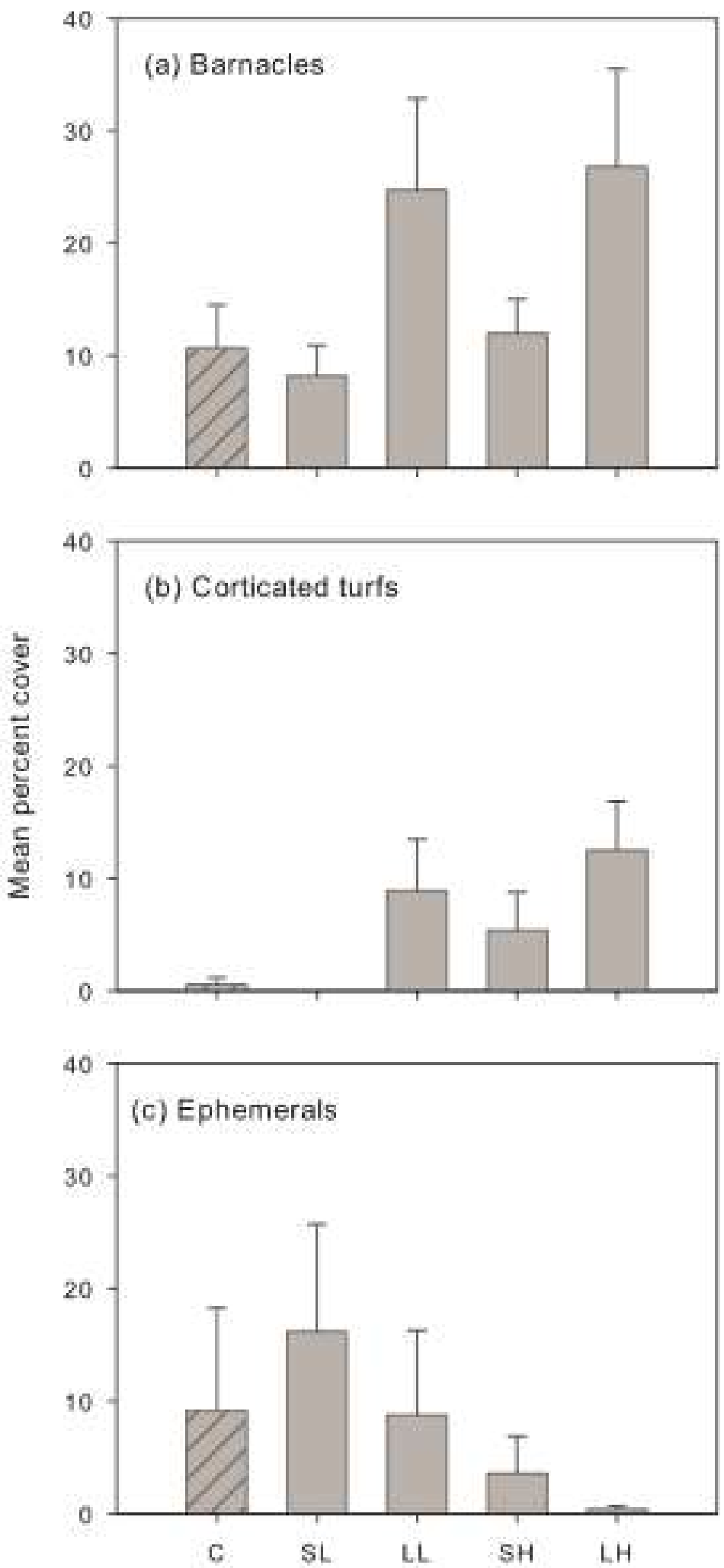

Fig. 2 
690

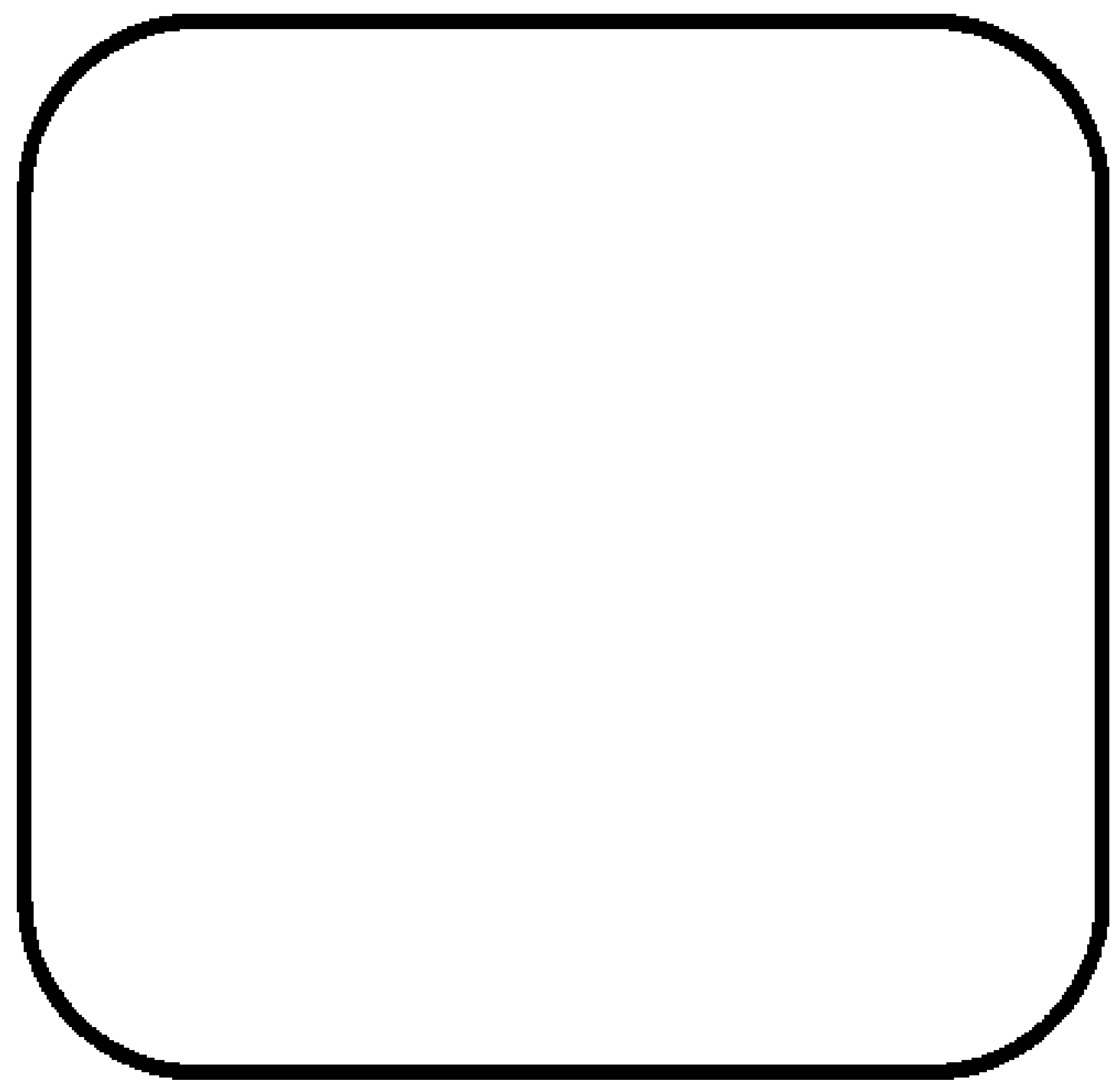

692 Fig. 3 